\title{
Choice of pharmacy, professional perceptions, and career plans of students in three Nigerian schools of pharmacy
}

\author{
Abdulmuminu Isah ${ }^{1}{ }^{\mathbb{D}}$, Adaobi Uchenna Mosanya ${ }^{1}{ }^{\mathbb{D}}$, Ugonna Augustine Enwereakuh ${ }^{1}{ }^{\mathbb{D}}$, Hadiza Usman \\ Ma'aji2 $^{(\mathbb{D})}$, Onyinye Blessing Ukoha-Kalu ${ }^{1}{ }^{(\mathbb{D}}$, Isaac Chijoke Ibezim ${ }^{1}{ }^{(\mathbb{D})}$, Chigozie Gloria Anene-Okeke ${ }^{1}{ }^{(\mathbb{D})}$, \\ Chukwuemeka Michael Ubaka ${ }^{1}$ iD \\ 1 Department of Clinical Pharmacy and Pharmacy Management, Faculty of Pharmaceutical Sciences, University of Nigeria, Nigeria \\ 2 Department of Clinical Pharmacy and Pharmacy Practice, Faculty of Pharmaceutical Sciences, Ahmadu Bello University, Nigeria
}

\author{
Keywords \\ Career choice \\ Nigeria \\ Perception \\ Pharmacy \\ Profession \\ Students \\ University
}

\author{
Correspondence \\ Adaobi Uchenna Mosanya \\ Department of Clinical Pharmacy and \\ Pharmacy Management \\ Faculty of Pharmaceutical Sciences \\ University of Nigeria \\ Nsukka \\ Nigeria \\ adaobi.mosanya@unn.edu.ng
}

\begin{abstract}
Background: A progressive increase in the number of students admitted to study pharmacy in Nigeria has not been met with sufficient documented evidence of their preferences and motivations. Studies on this would aid in designing a programme that matches student expectations, whilst maintaining regulatory requirements. Aim: This study evaluated students' preferences in wanting to study pharmacy, perceptions of the profession and career choice. Method: A cross-sectional questionnaire-based study was conducted among students of all study years across three Nigerian Schools of Pharmacy after obtaining approval from their managements. Data analysis was conducted using descriptive and inferential statistics. Results: The response rate of the study was $87.5 \%$. Most students from the three universities reported a preference for pharmacy as their first choice of course: 733 (86.0\%) for University of Nigeria (UNN), 66 (71.7\%) for Nnamdi Azikiwe University (NAU) and 48 (45.3\%) for Enugu State University of Science and Technology (ESUT). The students' mean perception of pharmacy was $77.6 \pm 13.5 \%$. However, 69.1\% (UNN), 64.1\% (NAU) and $59.4 \%$ (ESUT) students preferred academic pharmacy to other practice areas in pharmacy.

Conclusions: Pharmacy was the preferred course of choice for most students currently enrolled in the programme. The students had generally positive perceptions towards the profession.
\end{abstract}

\section{Introduction}

Numerous factors influence the choice of a university undergraduate degree programme by high school leavers. Examples of such factors include interest in science subjects (like chemistry, mathematics, biology, and physics), the expectation of a highly paid profession after graduation, the availability of job opportunities, the reputation of the university, and influence of relatives and friends (Ferguson et al., 1986); The Pharmacy programme has become a course of choice for many students due to some of these reasons. Pharmacists play vital roles in healthcare delivery, especially with the progressive advancement of pharmacy education and practice. This advancement has led to pharmaceutical care delivery which aims to optimise the outcomes of drug therapy by focusing on individual patients rather than the drugs (Alhaddad, 2018). Some students, however, come into pharmacy as their second-choice course with medicine being their preferred choice (Alhaddad, 2018). Some of the factors that deter prospective students from enrolling into pharmacy schools are the cost and duration of the programme. The high cost of tuition for pharmacy programmes has been shown to affect the motivation of students in choosing pharmacy as undergraduate degree programmes (Shaikh, 2013).

There has been a progressive increase in the number of students admitted to study pharmacy in Nigerian 
universities. However, there is no sufficient documented evidence to show if such students enrolled at the undergraduate level of their volition. This information is vital, considering that many graduates from Nigeria pharmacy schools not only practice in the country but migrate to practice in other countries. An understanding of the preference and motivations of the students to study pharmacy would also help to design a programme that matches their expectations, while maintaining regulatory requirements.

\section{Objective}

This study was conducted to assess students' preference to study pharmacy, their perception towards the profession and their career plans in three Nigerian schools of pharmacy.

\section{Methods}

\section{The Study Design}

This study adopted a cross-sectional questionnaire-based design in three Nigerian schools of pharmacy.

\section{Participants}

This study did not involve members of the general public or patients, thus it was deemed to be exempt from an ethical approval from the institutional review board. Nonetheless, permission was obtained from the Deans of the three Pharmacy schools that were used for the study before the students were contacted. No identifiable information was obtained from the students, and no information that could compromise any participant's confidentiality was presented in the results and any other part of the study. The participants were undergraduate pharmacy students in all years of study.

\section{Instrument}

The structured questionnaire used for this study was developed based on previous studies that assessed outcome variables that were similar to those considered in this study (Alhaddad, 2018; Capstick et al., 2007; Hanna et al., 2016; James et al., 2018; Jesson et al., 2010). The questionnaire was content validated by experienced faculty members of the Department of Clinical Pharmacy and Pharmacy Management, University of Nigeria (UNN). The questionnaire was piloted for face-validation with ten pharmacy students of UNN. Those students were subsequently excluded from participating in the final study. Modifications to the survey questionnaire were made based on the feedback from both faculty and students. Acceptable reliability was achieved by determining the Cronbach's alpha of the instrument before it was used for the study.

The final version of the questionnaire had five sections. The first section recorded respondents' demographic characteristics, for example, age, gender, year of study, cumulative gross point average (CGPA), and qualifications. The last two demographic responses were self-reported and could not be verified from the institutions because no identifier information was obtained in order to maintain the confidentiality of the respondents, in addition to the fact that the schools would not provide such personal information. The second section enquired about students' preference for their choice of pharmacy. The third section asked about the factors that motivated them to be pharmacy students. The fourth section measured the students' perceptions of the pharmacy profession, while the final section documented their career plans upon graduation. The last four sections all had close-ended questions.

\section{Study settings and questionnaire distribution}

The study settings were: the UNN, a federal university located in Nsukka, Enugu State, Nnamdi Azikiwe University (NAU), Awka, Anambra State and Enugu State University of Science and Technology (ESUT). These schools were purposively selected as the only schools of pharmacy in south-eastern Nigeria. All the pharmacy students present in all the classes of the three schools during the second semester of the 2017/2018 session were invited to participate in the study. A total of 1200 questionnaires were administered to students from the schools. The questionnaires were distributed to the various schools separately and collated as such. Hence, they were not mixed-up that would require sorting after the collation. The students did not receive prior information about the study. Rather, a written invitation was provided to the students on the spot which introduced the study and its purpose, in addition to the assurances of confidentiality. Only the students who provided written informed consent to participate in the study were given the questionnaires, which were returned after about ten to 15 minutes. The students were encouraged to maintain independence while responding to the questions. To maximise the response rate, the questionnaires were distributed immediately after a lecture that was offered by all the students. 


\section{Data analysis}

The collected questionnaires were screened for valid responses. Only those that had the sociodemographic section filled were used for the study. The eligible questionnaires were coded into Microsoft Excel (2019) and cleaned to ensure correctness in transcribing the responses. The data was then exported to IBM Statistical Product and Services Solution (Version 25), which was used for analysis. The students' responses to the questions were presented with such descriptive statistics as means, frequencies and percentages. Chi-square test was used to determine the relationship between the respondents' choice of pharmacy and the factors that motivated them as pharmacy students. Chi-square test was also conducted to determine the association between the respondents' sociodemographic characteristics and their perception of pharmacy as well as their career plans. Statistical significance for the inferential statistics was assumed for $p$ values below 0.05 .

\section{Results}

The total number of students that responded to the questionnaire was 1050 (87.5\% response rate): 852 of 948 in UNN (89.9\%), 92 of 133 in NAU (69.2\%), and 106 of 119 in ESUT (89.1\%). The majority of pharmacy students at UNN $(455,53.4 \%)$ and NAU $(59,64.1 \%)$ were aged between 21-25 years, while a student from ESUT was aged between 16-20 years. Most students from UNN and ESUT were females; 470 (55.2\%) and 54 (50.9\%), respectively, while male students were the majority in NAU $(49,53.3 \%)$. See Table I for a full breakdown of results.

Most students from the three universities reported a preference for pharmacy as the course of their first choice: 733 (86.0\%) for UNN, 66 (71.7) for NAU, and 48 (45.3\%) for ESUT. The Bachelor of Pharmacy (B.Pharm.) was the preferred programme in all three schools, with 87 (94.6\%) of NAU students preferring it to Doctor of Pharmacy (Pharm. D.), see Table II.

There was a significant relationship between the year of study and students showing a preference for pharmacy in UNN ( $p=0.003)$ and ESUT $(p=0.002)$, while age was related to the preferences of ESUT students $(p=0.019)$, see Table III.

Table IV shows that family encouragement was considered to be a motive for the choice of pharmacy in all the three universities, with 553 (64.9\%) of UNN, 60 (65.2\%) of NAU and 59 (55.7\%) of ESUT students. Student performance in science-based courses was considered a strong reason for the choice of pharmacy by students from all the three schools: $80.6 \%$ for UNN, $77.2 \%$ for NAU, $67.0 \%$ for ESUT students. A need to work with patients was also considered a strong reason to study pharmacy by students from all the three schools, with $67.3 \%$ of UNN students, $66.3 \%$ of NAU and $54.7 \%$ of ESUT.

The mean perception score towards the pharmacy profession was $77.6 \pm 13.6 \%$. (Table V) In UNN, there was the highest portion of students with a good perception of the pharmacy programme $(472,55.4 \%)$. Whilst for students of NAU $(49,53.3 \%)$ and ESUT $(54,50.9 \%)$, the majority. of students had a poor perception of the pharmacy programme.

In Table VI, it is shown that there is a significant relationship between career choice and choice of pharmacy as the course of first choice, with the pharmaceutical industry choice as a career that shows a strong relationship for the students from UNN

Table I: Sociodemographic Characteristics of Pharmacy Students

\begin{tabular}{|c|c|c|c|c|c|c|c|}
\hline \multirow{2}{*}{\multicolumn{2}{|c|}{ Characteristics }} & \multicolumn{2}{|c|}{ UNN } & \multicolumn{2}{|c|}{ NAU } & \multicolumn{2}{|c|}{ ESUT } \\
\hline & & \multirow{2}{*}{$\begin{array}{l}n \\
322\end{array}$} & \multirow{2}{*}{$\begin{array}{l}\% \\
37.8\end{array}$} & \multirow{2}{*}{$\begin{array}{l}n \\
23\end{array}$} & \multirow{2}{*}{$\begin{array}{l}\% \\
25.0\end{array}$} & \multirow{2}{*}{$\begin{array}{l}n \\
65\end{array}$} & \multirow{2}{*}{$\begin{array}{l}\% \\
61.3\end{array}$} \\
\hline Age (Years) & $16-20$ & & & & & & \\
\hline & $21-25$ & 455 & 53.4 & 59 & 64.1 & 39 & 36.8 \\
\hline & $26-30$ & 67 & 7.9 & 5 & 5.4 & 2 & 1.9 \\
\hline & $31-35$ & 5 & 0.6 & 4 & 4.3 & - & - \\
\hline & $>35$ & 3 & 0.4 & 1 & 1.1 & - & - \\
\hline & Total & 852 & 100.0 & 92 & 100.0 & 106 & 100.0 \\
\hline \multirow[t]{3}{*}{ Gender } & Male & 382 & 44.8 & 49 & 53.3 & 52 & 49.1 \\
\hline & Female & 470 & 55.2 & 43 & 46.7 & 54 & 50.9 \\
\hline & Total & 852 & 100.0 & 92 & 100.0 & 106 & 100.0 \\
\hline \multirow[t]{3}{*}{ Entry } & UTME & 769 & 90.5 & 81 & 88.0 & 104 & 99.0 \\
\hline & $\mathrm{DE}$ & 81 & 9.5 & 11 & 12.0 & 1 & 1.0 \\
\hline & Total & 850 & 100.0 & 92 & 100.0 & 105 & 100.0 \\
\hline \multirow[t]{6}{*}{ Year of Study } & First & 146 & 17.1 & 1 & 1.1 & 20 & 18.9 \\
\hline & Second & 187 & 21.9 & 35 & 38.0 & 32 & 30.2 \\
\hline & Third & 214 & 25.1 & 13 & 14.1 & 41 & 38.7 \\
\hline & Fourth & 119 & 14.0 & 18 & 19.6 & 1 & 0.9 \\
\hline & Fifth & 186 & 21.8 & 25 & 27.2 & 12 & 11.3 \\
\hline & Total & 852 & 100.0 & 92 & 100.0 & 106 & 100.0 \\
\hline \multirow[t]{3}{*}{ Residence } & Urban & 721 & 84.6 & 69 & 75.0 & 90 & 84.9 \\
\hline & Rural & 131 & 15.4 & 23 & 25.0 & 16 & 15.1 \\
\hline & Total & 852 & 100.0 & 92 & 100.0 & 106 & 100.0 \\
\hline \multirow[t]{6}{*}{ CGPA } & Not Indicated & 32 & 3.8 & - & - & - & - \\
\hline & $1.5-2.39$ & 14 & 1.6 & 2 & 2.2 & 2 & 1.9 \\
\hline & $2.40-3.49$ & 45 & 5.3 & 4 & 4.3 & 22 & 20.8 \\
\hline & $3.50-4.49$ & 657 & 77.1 & 64 & 69.6 & 62 & 58.5 \\
\hline & $>4.5$ & 104 & 12.2 & 22 & 23.9 & 20 & 18.9 \\
\hline & Total & 852 & 100.0 & 92 & 100.0 & 106 & 100.0 \\
\hline \multirow[t]{5}{*}{ Qualification } & SSCE & 728 & 85.4 & 76 & 82.6 & 89 & 84.0 \\
\hline & ND & 11 & 1.3 & - & - & 3 & 2.8 \\
\hline & B.Sc & 85 & 10.0 & 12 & 13.0 & 9 & 8.5 \\
\hline & Others & 28 & 3.3 & 4 & 4.3 & 5 & 4.7 \\
\hline & Total & 852 & 100.0 & 92 & 100.0 & 106 & 100.0 \\
\hline
\end{tabular}


Table II: Pharmacy students' preference for pharmacy course and programme

\begin{tabular}{llcccccc}
\hline & & \multicolumn{2}{c}{ UNN } & \multicolumn{2}{c}{ NAU } & \multicolumn{2}{c}{ ESUT } \\
& & $\mathrm{n}$ & $\%$ & $\mathrm{n}$ & $\%$ & $\mathrm{n}$ & $\%$ \\
\hline Choice of & First & $\mathbf{7 3 3}$ & $\mathbf{8 6 . 0}$ & $\mathbf{6 6}$ & $\mathbf{7 1 . 7}$ & $\mathbf{4 8}$ & $\mathbf{4 5 . 3}$ \\
Pharmacy & Second & 48 & 5.6 & 11 & 12.0 & 23 & 21.7 \\
& Neither & 71 & 8.3 & 15 & 16.3 & 35 & 33.0 \\
& Total & 852 & 100.0 & 92 & 100.0 & 106 & 100.0 \\
First choice & B.Pharm. & $\mathbf{7 3 2}$ & $\mathbf{8 5 . 9}$ & $\mathbf{8 7}$ & $\mathbf{9 4 . 6}$ & $\mathbf{6 8}$ & $\mathbf{6 4 . 2}$ \\
programme & Pharm.D. & 120 & 14.1 & 5 & 5.4 & 38 & 35.8 \\
& Total & 852 & 100.0 & 92 & 100.0 & 106 & 100.0 \\
Has a parent & No & $\mathbf{6 6 2}$ & $\mathbf{7 7 . 7}$ & $\mathbf{7 4}$ & $\mathbf{8 0 . 4}$ & $\mathbf{9 3}$ & $\mathbf{8 7 . 7}$ \\
working in & Yes & 190 & 22.3 & 18 & 19.6 & 13 & 12.3 \\
pharmacy & Total & 852 & 100.0 & 92 & 100.0 & 106 & 100.0 \\
& & & & & & &
\end{tabular}

Table III: Relationship between students' sociodemographic characteristics and their preference for pharmacy as first choice

\begin{tabular}{|c|c|c|c|c|c|c|c|}
\hline & Age & Gender & $\begin{array}{l}\text { Entry } \\
\text { Mode }\end{array}$ & $\begin{array}{l}\text { Level } \\
\text { of } \\
\text { study }\end{array}$ & $\begin{array}{c}\text { Entry } \\
\text { Qualification }\end{array}$ & $\begin{array}{c}\text { Residence } \\
\text { (Rural or } \\
\text { Urban) }\end{array}$ & $\begin{array}{c}\text { Has a } \\
\text { parent } \\
\text { working in } \\
\text { pharmacy }\end{array}$ \\
\hline $\begin{array}{l}\text { UNN } \\
\text { (p-values) }\end{array}$ & 0.700 & 0.336 & 0.942 & 0.003 & 0.671 & 0.373 & 0.700 \\
\hline $\begin{array}{l}\text { NAU } \\
\text { (p-values) }\end{array}$ & 0.743 & 0.762 & 0.282 & 0.733 & 0.436 & 0.188 & 0.750 \\
\hline $\begin{array}{l}\text { ESUT } \\
\text { (p-values) }\end{array}$ & 0.019 & 0.586 & 0.549 & 0.002 & 0.058 & 0.430 & 0.321 \\
\hline
\end{tabular}

( $p \leq 0.0001)$, a significant relationship between community pharmacy and choice was shown in ESUT ( $p=$ 0.030 ). There was significant relationship between age ( $p=$ $0.016)$, gender $(p=0.012)$ and study year $(p \leq 0.0001)$ with career plans among UNN students (Table VII).

\section{Discussion}

This study determined the preference of undergraduate pharmacy students in three Nigerian public universities (UNN, NAU, and ESUT) for the pharmacy programme that they were currently enrolled in. The study also identified the factors that motivated them to study the pharmacy course. The students' perceptions of the profession and career plans upon graduation from the universities were also determined. The response rates of the study in the three schools where the study was conducted were considered good, although UNN had a proportionately higher number of respondents than the others. That is most probably because UNN is far older than NAU and ESUT, as well as the prestige of being the first Federal
University in Nigeria after independence, hence the name: University of Nigeria. However, the students of the three schools have similar sociodemographic characteristics. Almost all the students were under 30 years of age, which is the average age of most undergraduate students in Nigeria. Gender distribution shows that there was an almost equal proportion of male and female students. Most of the students who responded to the questionnaire had a very good academic footing, with the self-reported CGPA ranging from 2.4 to 4.5 on a 5.0 scale.

On the preference to study pharmacy, this study discovered that the pharmacy programme was the course of choice for the majority of the students who were enrolled in the three universities. The fact that most students chose pharmacy as their first choice, shows the increased acceptability of the pharmacy profession. Other researchers have suggested that most students who studied pharmacy did so as a second choice to medicine (Alhaddad, 2018; James et al., 2018; Jesson et al., 2009). However, a New Zealand study conducted showed a similar result to that presented by this study (Capstick et al., 2007). The preference for B.Pharm. is attributable to the fact that the Pharm.D. programme has just recently been approved in Nigeria in 2018. Family influence played a very strong role in students' choice of the pharmacy programme in this study. The result is supported by studies in other countries (Hanna et al., 2016; James et al., 2018). Studies from the United Kingdom (UK) and Sierra Leone show that teachers also play a role in the students' choice (Hastings \& West, 2001; James et al., 2018).

Majority of the students from all the three universities agreed that pharmacy is an ideal profession, that they would choose pharmacy all over again, and want a career in pharmacy. Although there was no significant relationship between these parameters and students' choice, a significant relationship was reported by Alhaddad (2018). This suggests that the students are strongly motivated and satisfied with the pharmacy programme. This is obvious from their CGPA which showed satisfactory performance. Most students from UNN and NAU would not want a second degree after pharmacy. However, a good number of ESUT students would consider a second degree. This can be attributed to the majority of the students being between their first and third year of study and may not yet have a full understanding as the pharmacy programme in ESUT is still in its infancy. Another reason could be as a result of the students not yet having engaged in industrial training, which usually commences from the third year of study. A UK based study suggests that there could be a goal shift if students are not well motivated from a programme 
Table IV: Reasons for Pharmacy Students' Preference for Pharmacy and the Relationship with it as Course of Study

\begin{tabular}{|c|c|c|c|c|c|c|c|c|c|}
\hline \multirow[b]{2}{*}{ Reasons (Yes) } & \multicolumn{4}{|c|}{ UNN ( $N=852)$} & \multicolumn{2}{|c|}{ NAU (N = 92) } & \multicolumn{3}{|c|}{ ESUTH $(N=106)$} \\
\hline & $\mathbf{n}$ & $\%$ & $\begin{array}{l}\text { Choice } \\
\text { (p-value) }\end{array}$ & $\mathbf{n}$ & $\%$ & $\begin{array}{l}\text { Choice } \\
\text { (p-value) }\end{array}$ & $\mathbf{n}$ & $\%$ & $\begin{array}{l}\text { Choice } \\
\text { (p-value) }\end{array}$ \\
\hline Family encouragement & 553 & 64.9 & 0.815 & 60 & 65.2 & 0.548 & 59 & 55.7 & 0.216 \\
\hline Friends encouragement & 328 & 38.5 & 0.471 & 35 & 38.0 & 0.269 & 35 & 33.0 & 0.371 \\
\hline Teacher advised me & 156 & 18.3 & 0.131 & 15 & 16.3 & 0.368 & 15 & 14.2 & 0.811 \\
\hline University gave me & 326 & 38.3 & 0.118 & 52 & 56.5 & 0.023 & 70 & 66.0 & 0.052 \\
\hline Was good at science courses & 687 & 80.6 & 0.075 & 71 & 77.2 & 0.878 & 71 & 67.0 & 0.491 \\
\hline Is a respected profession & 671 & 78.8 & 0.200 & 71 & 77.2 & 0.223 & 75 & 70.8 & 0.937 \\
\hline In-demand career & 675 & 79.2 & 0.937 & 70 & 76.1 & 0.053 & 75 & 70.8 & 0.909 \\
\hline Work with patients & 573 & 67.3 & 0.554 & 61 & 66.3 & 0.471 & 58 & 54.7 & 0.447 \\
\hline Flexible working hours & 454 & 53.3 & 0.230 & 49 & 53.3 & 0.480 & 54 & 50.9 & 0.053 \\
\hline Work in health-related field & 735 & 86.3 & 0.500 & 80 & 87.0 & 0.125 & 84 & 79.2 & 0.158 \\
\hline Closest to profession medicine & 315 & 37.0 & 0.001 & 37 & 40.2 & 0.534 & 43 & 40.6 & 0.004 \\
\hline Good job opportunities & 319 & 37.4 & 0.589 & 40 & 43.5 & 0.003 & 43 & 40.6 & 0.070 \\
\hline Having direct patient contact & 523 & 61.4 & 0.618 & 62 & 67.4 & 0.395 & 52 & 49.1 & 0.707 \\
\hline Having a secured job & 578 & 67.8 & 0.661 & 64 & 69.6 & 0.225 & 68 & 64.2 & 0.101 \\
\hline University prospectus & 231 & 27.1 & 0.848 & 28 & 30.4 & 0.139 & 25 & 23.6 & 0.359 \\
\hline Radio/TV pharmacy program & 152 & 17.8 & 0.550 & 18 & 19.6 & 0.195 & 22 & 20.8 & 0.219 \\
\hline Family who owns pharmacy & 129 & 15.1 & 0.317 & 16 & 17.4 & 0.090 & 13 & 12.3 & 0.284 \\
\hline Pharmacy assistance experience & 134 & 15.7 & 0.061 & 21 & 22.8 & 0.457 & 16 & 15.1 & 0.158 \\
\hline Pharmacist role model & 331 & 38.8 & 0.026 & 43 & 46.7 & 0.003 & 35 & 33.0 & 0.227 \\
\hline
\end{tabular}

Table V: Pharmacy Students' Perception towards Choice of Pharmacy as a Career

\begin{tabular}{|c|c|c|c|c|c|c|c|c|c|c|}
\hline \multirow[t]{2}{*}{ Perception } & & \multicolumn{3}{|c|}{ UNN ( $N=852)$} & \multicolumn{3}{|c|}{ NAU (N = 92) } & \multicolumn{3}{|c|}{ ESUTH (N = 106) } \\
\hline & & $\mathbf{n}$ & $\%$ & Choice ( $p$-value) & $\mathbf{n}$ & $\%$ & Choice ( $p$-value) & $\mathbf{n}$ & $\%$ & Choice( $p$-value) \\
\hline \multirow{5}{*}{ Pharmacy is an ideal profession } & SD & 45 & 5.3 & 0.102 & 3 & 3.3 & 0.363 & 3 & 2.8 & 0.347 \\
\hline & $\mathrm{D}$ & 55 & 6.5 & & 9 & 9.8 & & 2 & 1.9 & \\
\hline & $\mathrm{N}$ & 179 & 21.0 & & 26 & 28.3 & & 30 & 28.3 & \\
\hline & A & 296 & 34.7 & & 18 & 19.6 & & 41 & 38.7 & \\
\hline & SA & 277 & 32.5 & & 36 & 39.1 & & 30 & 28.3 & \\
\hline \multirow{5}{*}{$\begin{array}{l}\text { I would choose pharmacy all over } \\
\text { again }\end{array}$} & SD & 50 & 5.9 & 0.009 & 6 & 6.5 & 0.564 & 7 & 6.6 & 0.201 \\
\hline & $\mathrm{D}$ & 80 & 9.4 & & 9 & 9.8 & & 12 & 11.3 & \\
\hline & $\mathrm{N}$ & 145 & 17.0 & & 23 & 25.0 & & 33 & 31.1 & \\
\hline & A & 269 & 31.6 & & 26 & 28.3 & & 24 & 22.6 & \\
\hline & SA & 308 & 36.2 & & 28 & 30.4 & & 30 & 28.3 & \\
\hline \multirow{5}{*}{ Want a career in pharmacy } & SD & 18 & 2.1 & 0.103 & 3 & 3.3 & 0.103 & 1 & 0.9 & 0.049 \\
\hline & $\mathrm{D}$ & 10 & 1.2 & & 2 & 2.2 & & 2 & 1.9 & \\
\hline & $\mathrm{N}$ & 104 & 12.2 & & 16 & 17.4 & & 22 & 20.8 & \\
\hline & A & 348 & 40.8 & & 31 & 33.7 & & 36 & 34.0 & \\
\hline & SA & 372 & 43.7 & & 40 & 43.5 & & 45 & 42.5 & \\
\hline \multirow{5}{*}{$\begin{array}{l}\text { Undertake second degree after } \\
\text { pharmacy }\end{array}$} & SD & 179 & 21.0 & 0.953 & 21 & 22.8 & 0.391 & 5 & 4.7 & 0.630 \\
\hline & $\mathrm{D}$ & 162 & 19.0 & & 14 & 15.2 & & 16 & 15.1 & \\
\hline & $\mathrm{N}$ & 200 & 23.5 & & 32 & 34.8 & & 27 & 25.5 & \\
\hline & A & 171 & 20.1 & & 10 & 10.9 & & 24 & 22.6 & \\
\hline & SA & 140 & 16.4 & & 15 & 16.3 & & 34 & 32.1 & \\
\hline \multirow{5}{*}{ Regret entering pharmacy school } & SD & 553 & 64.9 & 0.521 & 47 & 51.1 & 0.432 & 54 & 50.9 & 0.390 \\
\hline & $D$ & 220 & 25.8 & & 26 & 28.3 & & 27 & 25.5 & \\
\hline & $\mathrm{N}$ & 59 & 6.9 & & 18 & 19.6 & & 21 & 19.8 & \\
\hline & A & 11 & 1.3 & & 1 & 1.1 & & 1 & 0.9 & \\
\hline & SA & 9 & 1.1 & & - & - & & 3 & 2.8 & \\
\hline \multirow{5}{*}{$\begin{array}{l}\text { Would change degree to better } \\
\text { paying job }\end{array}$} & SD & 393 & 46.1 & 0.022 & 25 & 27.2 & 0.805 & 30 & 28.3 & 0.023 \\
\hline & D & 257 & 30.2 & & 35 & 38.0 & & 30 & 28.3 & \\
\hline & $\mathrm{N}$ & 119 & 14.0 & & 22 & 23.9 & & 30 & 28.3 & \\
\hline & A & 49 & 5.8 & & 5 & 5.4 & & 7 & 6.6 & \\
\hline & SA & 34 & 4.0 & & 5 & 5.4 & & 9 & 8.5 & \\
\hline
\end{tabular}


Table VI: Pharmacy students' future career plans and it's association with the choice of pharmacy as the student's preferred course of study

\begin{tabular}{|c|c|c|c|c|c|c|c|c|c|c|}
\hline \multirow[b]{2}{*}{ Career Plan } & & \multicolumn{4}{|c|}{ UNN ( $N=852)$} & \multicolumn{2}{|c|}{ NAU (N=92) } & \multicolumn{3}{|c|}{ ESUT $(N=106)$} \\
\hline & & $\mathbf{n}$ & $\%$ & $\begin{array}{l}p \text {-value for } \\
\text { Choice (Yes) }\end{array}$ & $\mathrm{n}$ & $\%$ & $\begin{array}{l}p \text {-value for } \\
\text { Choice (Yes) }\end{array}$ & $\mathrm{n}$ & $\%$ & $\begin{array}{l}p \text {-value for } \\
\text { Choice (Yes) }\end{array}$ \\
\hline \multirow{2}{*}{ Hospital dispensing pharmacist } & No & 617 & 72.4 & 0.439 & 76 & 82.6 & 0.268 & 71 & 67.0 & 0.417 \\
\hline & Yes & 235 & 27.6 & & 16 & 17.4 & & 35 & 33.0 & \\
\hline \multirow{2}{*}{ Hospital clinical pharmacist } & No & 415 & 48.7 & 0.259 & 61 & 66.3 & 0.182 & 61 & 57.5 & 0.420 \\
\hline & Yes & 437 & 51.3 & & 31 & 33.7 & & 45 & 42.5 & \\
\hline \multirow{2}{*}{ Community pharmacist } & No & 335 & 39.3 & 0.425 & 47 & 51.1 & 0.030 & 67 & 63.2 & 0.863 \\
\hline & Yes & 517 & 60.7 & & 45 & 48.9 & & 39 & 36.8 & \\
\hline \multirow{2}{*}{ Industry } & No & 264 & 31.0 & $<0.001$ & 34 & 37.0 & 0.804 & 45 & 42.5 & 0.536 \\
\hline & Yes & 588 & 69.0 & & 58 & 63.0 & & 61 & 57.5 & \\
\hline \multirow{2}{*}{ Academia } & No & 589 & 69.1 & 0.140 & 59 & 64.1 & 0.323 & 63 & 59.4 & 0.381 \\
\hline & Yes & 263 & 30.9 & & 33 & 35.9 & & 43 & 40.6 & \\
\hline \multirow{2}{*}{ Research } & No & 355 & 41.7 & 0.432 & 33 & 35.9 & 0.623 & 60 & 56.6 & 0.425 \\
\hline & Yes & 497 & 58.3 & & 59 & 64.1 & & 46 & 43.4 & \\
\hline \multirow{2}{*}{ Pharmaceutical marketing } & No & 428 & 50.3 & 0.181 & 61 & 66.3 & 0.174 & 59 & 55.7 & 0.136 \\
\hline & Yes & 424 & 49.7 & & 31 & 33.7 & & 47 & 44.3 & \\
\hline \multirow{2}{*}{ Regulatory and administration } & No & 339 & 39.8 & 0.352 & 41 & 44.6 & 0.748 & 55 & 51.9 & 0.370 \\
\hline & Yes & 513 & 60.2 & & 51 & 55.4 & & 51 & 48.1 & \\
\hline \multirow{2}{*}{ Work outside pharmacy } & No & 515 & 60.4 & 0.819 & 51 & 55.4 & 0.841 & 68 & 64.2 & 0.017 \\
\hline & Yes & 337 & 39.6 & & 41 & 44.6 & & 38 & 35.8 & \\
\hline \multirow{2}{*}{ Work outside Nigeria } & No & 202 & 23.7 & 0.975 & 32 & 34.8 & 0.041 & 30 & 28.3 & 0.957 \\
\hline & Yes & 650 & 76.3 & & 60 & 65.2 & & 76 & 71.7 & \\
\hline \multirow{2}{*}{ Undecided for now } & No & 742 & 87.1 & 0.657 & 83 & 90.2 & 0.482 & 93 & 87.7 & 0.234 \\
\hline & Yes & 110 & 12.9 & & 9 & 9.8 & & 13 & 12.3 & \\
\hline \multirow{2}{*}{$\begin{array}{l}\text { Complementary and alternative } \\
\text { medicine }\end{array}$} & No & 628 & 73.7 & 0.839 & 71 & 77.2 & 0.497 & 75 & 70.8 & 0.657 \\
\hline & Yes & 224 & 26.3 & & 21 & 22.8 & & 31 & 29.2 & \\
\hline
\end{tabular}

Table VII: Pharmacy students' future career plans and association with their demographic characteristics

\begin{tabular}{|c|c|c|c|c|c|c|c|c|c|}
\hline \multirow{3}{*}{ Career Plan } & \multicolumn{3}{|c|}{ UNN } & \multicolumn{3}{|c|}{ NAU } & \multicolumn{3}{|c|}{ ESUT } \\
\hline & Age & Gender & Study Year & Age & Gender & Study Year & Age & Gender & Study Year \\
\hline & \multicolumn{9}{|c|}{ ( $p$-value) } \\
\hline Hospital dispensing pharmacist & 0.016 & 0.012 & $<0.001$ & 0.138 & 0.402 & 0.831 & 0.389 & 0.450 & 0.224 \\
\hline Hospital clinical pharmacist & 0.409 & $<0.001$ & 0.008 & 0.218 & 0.504 & 0.369 & 0.956 & 0.449 & 0.397 \\
\hline Community pharmacist & $<0.001$ & 0.498 & $<0.001$ & 0.253 & 0.989 & 0.170 & 0.336 & 0.018 & 0.128 \\
\hline Industry & 0.070 & 0.117 & 0.001 & 0.476 & 0.027 & 0.054 & 0.680 & 0.266 & 0.604 \\
\hline Academia & 0.617 & 0.646 & 0.139 & 0.923 & 0.136 & 0.397 & 0.247 & $<0.001$ & 0.196 \\
\hline Research & 0.451 & 0.389 & 0.052 & 0.290 & 0.262 & 0.128 & 0.455 & 0.082 & 0.044 \\
\hline $\begin{array}{l}\text { Pharmaceutical sales } \\
\text { and marketing }\end{array}$ & 0.004 & 0.001 & 0.001 & 0.883 & 0.047 & 0.129 & 0.648 & 0.020 & 0.181 \\
\hline Regulatory and administrative & 0.909 & 0.193 & 0.022 & 0.130 & 0.625 & 0.587 & 0.388 & 0.246 & 0.052 \\
\hline Work outside pharmacy & 0.968 & 0.008 & 0.003 & 0.532 & 0.184 & 0.848 & 0.538 & 0.030 & 0.666 \\
\hline Work outside Nigeria & 0.031 & 0.229 & 0.177 & 0.876 & 0.182 & 0.480 & 0.553 & 0.903 & 0.249 \\
\hline Undecided for now & 0.035 & 0.041 & $<0.001$ & 0.749 & 0.885 & 0.608 & 0.591 & 0.415 & 0.369 \\
\hline $\begin{array}{l}\text { Complementary and Alternative } \\
\text { medicine }\end{array}$ & 0.375 & 0.946 & 0.379 & 0.685 & 0.927 & 0.711 & 0.331 & 0.233 & 0.457 \\
\hline
\end{tabular}


mastery mindset to a performance-based mindset (Hastings \& West, 2001; King, 2013). The work did not access the nature of students' motivation but goes on to show that they were well motivated.

A high proportion of students do not want a career in hospital dispensing pharmacy. The students from ESUT and NAU also do not want a career in hospital clinical pharmacy. An earlier study by Ubaka and colleagues (2014) suggested that pharmacy students in Nigeria preferred to practice in the hospital setting. This study suggests a shift in the students' focus. Results from Hanna and colleagues (2016) suggests a good number of UK pharmacy students want a career in hospital pharmacy. An issue pointed out by Ubaka and authors (2014) is the problem of the Nigerian pharmaceutical workforce capacity (number per population capita) being considered inadequate as Nigeria has reported 0.87 licensed pharmacists per 10000 individuals. Two thirds of the sampled students would not consider a career in alternative medicine.

The relationship between gender and hospital dispensing pharmacists was also observed in a study done in Saudi Arabia. The results had a strong relationship between gender and the choice of career in pharmaceutical sales and marketing (Alhaddad, 2018). However, there was no significant relationship between gender and a choice of career in regulatory and administrative pharmacy nor with research pharmacy, which contradicts the result obtained from the Saudi study (Alhaddad, 2018). Only students from ESUT showed a relationship between gender and the choice of a career in community practice similar to those observed in the study in Saudi Arabia.

This study has some limitations. In interpreting the findings of this study, it should be noted that the results cannot be generalised for all pharmacy schools in Nigeria. One reason is that the sample of universities are located geographically close in southeastern Nigeria. Despite being a limitation, the inclusion of UNN is a strength of the study, as it has the highest student enrolment of all pharmacy schools in Nigeria. Another limitation of the study is that the questionnaires were distributed only once in the study sites. Thus, students who were absent from school on the day that the researchers administered the questionnaires did not have the opportunity to participate in the study. But the response rate of the questionnaire administration showed that this limitation did not affect the findings of the study. It is recommended that further studies should consider a prospective design where there could be a measurement of the impact of interventions on orientations targeted at career guidance.
In addition, studies could also be conducted to determine the choices of students through their years of study in the pharmacy schools, from the first to the last.

It is concluded that Pharmacy was the preferred course of choice for most students currently enrolled in the programme in Nigeria. The students were motivated to study pharmacy as a result of: family influence, its closeness to the medical profession, a pharmacist role model, the family owning a pharmacy and it providing good job opportunities. They had a positive perception towards the pharmacy profession, but the majority where undecided on their career plans but would accept a career in community, academic or industrial pharmacy or practice abroad. These findings have implications for pharmacy education and practice. The regulators in charge of the curriculum design and monitoring could use these findings to identify the areas that need improvements in teaching and research. Moreover, professional organisations who would like to influence the career choices of students would find this study helpful in identifying the variables of intervention. This also holds for pharmaceutical organisations that would want to sway the perception of college students towards selecting a career in pharmacy.

\section{References}

Alhaddad, M.S. (2018). Undergraduate pharmacy students' motivations, satisfaction levels, and future career plans. Journal of Taibah University Medical Sciences, 13(3), 247-53. https:// doi.org/10.1016/i.jtumed.2018.03.004

Capstick, S., Green, J.A., \& Beresford, R. (2007). Choosing a course of study and career in pharmacy - student attitudes and intentions across three years at a New Zealand School of Pharmacy. Pharmacy Education, 7(4), 359-73. https://doi.org/ $\underline{10.1080 / 15602210701673811}$

Ferguson, J.A., Roller, L., \& Wertheimer, A. (1986). Social factors motivating students toward a career in pharmacy. Journal of Social and Administrative Pharmacy, 3, 59-66.

Hanna, L., Askin, F., \& Hall, M. (2016). First-Year Pharmacy Students' views on their chosen professional career. American Journal of Pharmaceutical Education, 80(9), article 150. https:// doi.org/10.5688/ajpe809150

Hastings, J.K., \& West, D.S. (2001) Pharmacy student motivation: Phase 1 of a Longitudinal Study. American Journal of Pharmaceutical Education, 65(September). https://doi.org/ 10.1.1.583.5796\&rep=rep1\&type=pdf

James, P.B., Batema, M.N.P., Bah, A.J., Brewah, T.S., Kella, A.T., Lahai, M., \& Jamshed, S.Q. (2018). Was pharmacy their preferred choice? assessing pharmacy students' motivation to study 
pharmacy, attitudes and future career intentions in Sierra Leone. Health Professions Education, 4(2), 139-148. http://dx.doi.org/ 10.1016/i.hpe.2017.06.001

Jesson, J., Langley, C., \& Wilson, K. (2009). Factors influencing students in choosing to study pharmacy in Great Britain (online). The Pharmaceutical Journal, (282), 750-753. Available from: https://www.semanticscholar.org/paper/Factors-influencingstudents-in-choosing-to-study-Jesson-Langley/ ca32740bcdc1bac889074687fc016d51968bcd91

Jesson, J., Langley, C., \& Wilson, K. (2010). Choosing to study pharmacy: measuring influences and motivations. Pharmacy Education, 10(March), 79-84. Available from: https:// pdfs.semanticscholar.org/399e/3b4b0cd322035a50c0f22

King, M.D. (2013) Motivation and education: performance, commitment, and satisfaction among pharmacy students (online). Graduate Student Theses, Dissertations, \& Professional Papers. 682. Available from: https://scholarworks.umt.edu/cgi/ viewcontent.cgi?article $=1701 \&$ context $=$ etd

Shaikh H., Elhissi, A.M.A., Vohra, S., Pearson, B.J., \& Taylor, K.M.G. (2013) Motivations of M. Pharm students in the United Kingdom to study pharmacy at a time of change. Pharmacy Education, 13(1), 187-91. Available from: https://pdfs.semanticscholar.org/ 1ed5/02d6b45e363ca73bd8db3236057cfe111fd3.pdf

Ubaka, C.M., Ochie, U.M., \& Adibe, M.O. (2013). Student pharmacists' career choices: a survey of three Nigerian schools of pharmacy. Pharmacy Practice, 11(3), 149-155. https://doi.org/ $\underline{10.4321 / \mathrm{s} 1886-36552013000300005}$ 